\title{
Prevalence and severity of vitamin D deficiency in patients with diabetic foot infection
}

\author{
Shalbha Tiwari ${ }^{1}$, Daliparthy D. Pratyush ${ }^{1}$, Balram Gupta ${ }^{1}$, Awanindra Dwivedi ${ }^{1}$, Sandeep Chaudhary $^{1}$, \\ Rammohan K. Rayicherla ${ }^{2}$, Sanjeev K. Gupta ${ }^{3}$ and Surya Kumar Singh ${ }^{1 *}$ \\ ${ }^{1}$ Department of Endocrinology and Metabolism, Institute of Medical Sciences, Banaras Hindu University, Varanasi 221005, \\ $U P$, India \\ ${ }^{2}$ Department of Medicine, Institute of Medical Sciences, Banaras Hindu University, Varanasi 221005, UP, India \\ ${ }^{3}$ Department of General Surgery, Institute of Medical Sciences, Banaras Hindu University, Varanasi 221005, UP, India
}

(Submitted 19 May 2011 - Final revision received 28 November 2011 - Accepted 30 January 2012 - First published online 3 April 2012)

\section{Abstract}

The aim of the present research was to study the prevalence and severity of vitamin D deficiency in patients with diabetic foot infection. Patients were enrolled in two groups: diabetic patients with foot infection ( $n$ 125) as cases and diabetic patients without the infection as controls ( $n$ 164). Serum 25-hydroxyvitamin D (25(OH)D) was measured by RIA. Data were presented as means and standard deviations unless otherwise indicated and were analysed by SPSS. Results revealed that 25(OH)D (nmol/l) was significantly lower (40.25 (sD $38 \cdot 35) v$. 50.75 (sD 33.00); $P<0.001)$ in cases than in controls. Vitamin D inadequacy $(25(\mathrm{OH}) \mathrm{D}<75 \mathrm{nmol} / \mathrm{l})$ was equally common in cases and controls (OR $1 \cdot 45,95 \%$ CI $0 \cdot 8,3 \cdot 0 ; P=0 \cdot 32)$, but cases had a greater risk of vitamin D deficiency $(25(\mathrm{OH}) \mathrm{D}<50 \mathrm{nmol} / \mathrm{l})$ than controls (OR 1.8, 95\% CI 1.1 3.0; $P=0 \cdot 02$ ). Risk of severe vitamin D deficiency $(25(\mathrm{OH}) \mathrm{D}<25 \mathrm{nmol} / \mathrm{l})$ was significantly higher in cases than in controls (OR 4.0, 95\% CI 2.4, 6.9; $P<0.0001$ ). Age, duration of diabetes and HbA1c were significantly higher in cases than in controls and therefore adjusted to nullify the effect of these variables, if any, on study outcome. The study concluded that vitamin D deficiency was more prevalent and severe in patients with diabetic foot infection. This study opens up the issue of recognising severe vitamin $\mathrm{D}$ deficiency $(<25 \mathrm{nmol} / \mathrm{l})$ as a possible risk factor for diabetic foot infections and the need for vitamin D supplementation in such patients for a better clinical outcome. This could be substantiated by similar data from future studies

\section{Key words: Diabetic foot infection: Vitamin D deficiency: Infection}

Vitamin $\mathrm{D}$ is a pleiotropic hormone known to play an immunomodulatory $\operatorname{role}^{(1,2)}$, in addition to $\mathrm{Ca}$ and bone metabolism. Receptors for its activated form have been identified on pancreatic $\beta$ cells and immune cells ${ }^{(3,4)}$. Evidence is available linking vitamin D deficiency with bacterial and viral infections $^{(5,6)}$. Foot infection accounts for $20 \%$ of hospitalisation of diabetic patients annually ${ }^{(7)}$. Immunological defects $^{(8)}$ in addition to neuropathy and vascular abnormality are the prime contributors in the pathogenesis of diabetic foot and subsequent infections. Different studies have shown that deficiency of vitamin D leads to immune cell dysfunction, $\beta$ cell damage and impaired insulin production ${ }^{(3,9,10)}$. In addition to hyperglycaemia, vitamin D deficiency could also be linked to an altered immune system of patients with diabetes, rendering them susceptible to foot infection and unfavourable prognosis. Thus, we were tempted to hypothesise vitamin D deficiency to be more common and severe in diabetic foot infected patients. We hence designed the present study to find out the prevalence and severity of vitamin $\mathrm{D}$ deficiency in patients with diabetic foot infection.

\section{Patients and methods}

\section{Patients}

In the present study, patients attending the diabetic foot and endocrine outpatient clinics of the University Hospital were enrolled. A total of 289 patients with diabetes were enrolled and divided into two groups depending on their presentation on clinical examination as cases and controls. Cases consisted of diabetic patients with clinical evidence of foot infection ( $n$ 125); diabetic patients without evidence of any systemic infection ( $n$ 164) served as controls. A detailed clinical history, including age, sex, duration of diabetes, and concomitant and anti-diabetic medications, was recorded on a preset proforma. Infection was clinically diagnosed by culture positivity and/or

Abbreviation: 25(OH)D, 25-hydroxyvitamin D

*Corresponding author: Professor S. K. Singh, fax +91 542 2369222, email sksendocrine@yahoo.com 
Table 1. Vitamin D status and other characteristics of study participants (Number of participants, mean values and standard deviations; mean values with their standard errors)

\begin{tabular}{|c|c|c|c|c|c|}
\hline & \multicolumn{2}{|c|}{ Cases } & \multicolumn{2}{|c|}{ Controls } & \multirow[b]{2}{*}{$P$} \\
\hline & Mean & SD & Mean & SD & \\
\hline$n$ & \multicolumn{2}{|c|}{125} & \multicolumn{2}{|c|}{164} & \\
\hline Male & \multicolumn{2}{|c|}{85} & \multicolumn{2}{|c|}{103} & \\
\hline Female & \multicolumn{2}{|c|}{40} & \multicolumn{2}{|c|}{61} & \\
\hline Age (years) & $53 \cdot 6$ & $10 \cdot 7$ & $51 \cdot 0$ & $10 \cdot 8$ & 0.039 \\
\hline DODM (years) & & & & & 0.049 \\
\hline Mean & \multicolumn{2}{|c|}{6.9} & \multicolumn{2}{|c|}{5.4} & \\
\hline SEM & \multicolumn{2}{|c|}{0.53} & \multicolumn{2}{|c|}{0.52} & \\
\hline $\mathrm{HbA} 1 \mathrm{c}(\mathrm{mmol} / \mathrm{mol})$ & 86 & $6 \cdot 0$ & 77 & 8.0 & 0.024 \\
\hline $\mathrm{BMI}\left(\mathrm{kg} / \mathrm{m}^{2}\right)$ & 24.0 & 3.7 & 24.7 & 4.2 & 0.246 \\
\hline $25(\mathrm{OH}) \mathrm{D}(\mathrm{nmol} / \mathrm{l})$ & 40.25 & 38.35 & $50 \cdot 75$ & 33.00 & 0.012 \\
\hline
\end{tabular}

DODM, duration of diabetes mellitus; 25(OH)D, 25-hydroxyvitamin D.

leucocytosis in the presence of fever. Patients having clinical evidence of vascular insufficiency or taking immunosuppressants, multivitamins, Ca supplements and drugs that interfere with vitamin D metabolism were excluded from the study. Cases and controls were simultaneously enrolled throughout the study period of 1 year. Informed written consent was obtained from all participants. This study was conducted according to the guidelines laid down in the Declaration of Helsinki and all procedures involving human subjects/patients were approved by Institute Ethics Committee, Banaras Hindu University.

\section{Sample collection}

Blood samples with and without anti-coagulant were collected for estimating glycosylated HbA1c and serum 25-hydroxyvitamin D (25(OH)D), respectively.

\section{Serum 25-hydroxyvitamin D assay}

Serum 25(OH)D was estimated by RIA using a commercial kit (Diasorin) following the manufacturer's protocol. All the tests were run in triplicates and tubes were counted for $60 \mathrm{~s}$. The mean of the three readings was taken to plot the graph and calculate the concentration of samples. Intra-assay and inter-assay CV were 11.7 and $12.5 \%$, respectively.

\section{Adequacy of vitamin $D$}

Different cut-offs of vitamin D were chosen, i.e. $<25,<50$ and $<75 \mathrm{nmol} / 1$ for evaluating the most appropriate risk factor in patients with diabetic foot infection. The three cut-offs of vitamin D deficiency chosen were in accordance with the recommendation of Endocrine Society practice guidelines $^{(11)}$ and Institute of Medicine definitions ${ }^{(12)}$, but in the context with its role in immune modulation and not with Ca homeostasis.

\section{Statistical analysis}

Data are presented as means and standard deviations unless otherwise indicated. Statistical analysis was conducted by using SPSS 16.0 (SPSS Inc.). Group means were compared by independent $t$ test and OR were calculated for the three study cut-offs of vitamin D deficiency to estimate the risk point for diabetic foot infection. Those variables that were significantly different in cases and controls and known to influence immune status were also adjusted independently before analysis.

\section{Results}

25(OH)D was significantly lower in patients with foot infection than in those without infection (40.25 (SD 38.35) $v .50 \cdot 75$ (SD 33.00); $P<0.001$ ) (Table 1). Prevalence of vitamin $\mathrm{D}$ inadequacy at the three study cut-offs chosen, i.e. $<75,<50$ and $<25 \mathrm{nmol} / 1$ was $87.4,70$ and $45.6 \%$, respectively, in cases, whereas the corresponding values in controls were $82 \cdot 6,56 \cdot 2$ and $17 \cdot 3 \%$.

To further specify the risk point of vitamin D deficiency for diabetic foot infection, OR were calculated (Table 2). Vitamin D inadequacy $(25(\mathrm{OH}) \mathrm{D}<75 \mathrm{nmol} / \mathrm{l})$ was equally common in cases and controls, but cases had a greater risk of having vitamin D level $<50 \mathrm{nmol} / 1$ than controls. Also, the risk of having severe vitamin $\mathrm{D}$ deficiency $(25(\mathrm{OH}) \mathrm{D}<25 \mathrm{nmol} / \mathrm{l})$ was much higher in cases than in controls. Factors such as age $(P=0.039)$, duration of diabetes $(P=0.049)$ and HbA1c ( $P=0.024)$ were significantly higher in cases than in controls, and were adjusted to nullify their effect, if any, on the test variable (Table 2). It was found that the outcome was similar to the observation without adjustment.

\section{Discussion}

In the present study, vitamin D status was evaluated in view of its immune-regulatory role in diabetic foot infected patients who are known to have immune dysfunction ${ }^{(13-15)}$ and susceptibility to microbial infection. The data analysis revealed

Table 2. Risk assessment of vitamin $D$ deficiency at three cut-off values for diabetic foot infection (Odds ratios and $95 \%$ confidence intervals)

\begin{tabular}{|c|c|c|c|c|c|c|c|c|}
\hline \multirow[b]{2}{*}{ Vitamin D cut-off } & \multirow[b]{2}{*}{ Unadjusted OR } & \multirow[b]{2}{*}{$95 \% \mathrm{Cl}$} & \multicolumn{2}{|c|}{ Age } & \multicolumn{2}{|c|}{$\mathrm{HbA1c}$} & \multicolumn{2}{|c|}{ Duration of diabetes } \\
\hline & & & Adjusted OR & $95 \% \mathrm{Cl}$ & Adjusted OR & $95 \% \mathrm{Cl}$ & Adjusted OR & $95 \% \mathrm{Cl}$ \\
\hline$<25 \mathrm{nmol} / \mathrm{l}$ & $4.0^{\star \star}$ & $2.4,6.9$ & $4 \cdot 3^{\star \star}$ & $2.5,7.5$ & $3 \cdot 7^{\star \star}$ & $2 \cdot 1,6 \cdot 4$ & $3.8^{\star \star}$ & $2 \cdot 0,7 \cdot 0$ \\
\hline$<50 \mathrm{nmol} / \mathrm{l}$ & $1 \cdot 8^{*}$ & $1 \cdot 1,3 \cdot 0$ & $1.9^{*}$ & $1 \cdot 2,3 \cdot 2$ & $1 \cdot 8^{*}$ & $1 \cdot 0,3 \cdot 0$ & 1.5 & $0 \cdot 9,2 \cdot 6$ \\
\hline$<75 \mathrm{nmol} / \mathrm{l}$ & 1.5 & $0.8,3.0$ & 1.7 & $0.8,3.5$ & 1.6 & $0.8,3.4$ & 1.9 & $0.9,4.0$ \\
\hline
\end{tabular}

${ }^{*} P<0.05,{ }^{* *} P<0.0001$ 
that the patients with foot infection had comparatively higher prevalence of vitamin D deficiency $(<50 \mathrm{nmol} / \mathrm{l})$ than those who had no evidence of infection $(71 \cdot 2 v .57 \cdot 3 \%)$. Prevalence of severe vitamin D deficiency $(<25 \mathrm{nmol} / \mathrm{l})$ was remarkably higher in cases $(46 \cdot 4 \%)$ than in controls (17.6\%). Foot infection in patients with diabetes reflects their poor immune status compared to patients with diabetes. Our assumption of the vitamin $\mathrm{D}$ deficiency in diabetic foot infection to be more common and severe was substantiated by the findings of the present study. Subjects who were enrolled as cases mostly belong to the rural part of northern India and due to the common practice they had comparatively more hours of daily sun exposure than the control subjects who were fit and indoor workers. Mobility was not a concern when sun exposure time was longer in cases than in controls. There was no difference in the sampling season of cases and controls. We were not intended to elaborate the cause of vitamin D deficiency in this study. We observed that irrespective of aetiology, vitamin $\mathrm{D}$ deficiency was common and severe in diabetic foot infection.

Researchers have linked vitamin D with several other immunological alterations that are associated with increased susceptibility towards infection. It has also been shown that active vitamin $\mathrm{D}_{3}$ stimulates the phagocytosis and killing of bacteria by macrophages ${ }^{(16)}$ and is a potent suppressor of interferon- $\gamma$-mediated macrophage activation ${ }^{(17)}$. It suppresses $\mathrm{T}$ cell proliferation and decreases the production of the $\mathrm{T}$ helper type 1 cytokines while promoting the production of T helper type 2 cytokines $^{(18)}$. T helper type 2 cells primarily play a role in response to extracellular pathogens (most bacteria and parasites). In addition to hyperglycaemia, deficiency of vitamin D might also increase the risk of infection in diabetic foot patients by further depleting the immune cells' response against infection. The role of vitamin $\mathrm{D}$ in defence against tuberculosis has been studied. It was shown that vitamin $\mathrm{D}$ modulates the immunological response to intracellular pathogen Mycobacterium tuberculosis particularly by inducing cathelicidin antimicrobial peptide gene expression ${ }^{(19)}$.

Studies have also shown the effect of vitamin D on glucose homeostasis, insulin resistance and $\beta$ cell dysfunction in subjects at risk of type 2 diabetes $^{(20)}$ and on markers of inflammation in non-diabetic adults ${ }^{(21)}$. Studies are lacking on vitamin D status of patients with diabetic foot infection and its effect on host defence. This study has $99 \%$ power to define $25(\mathrm{OH}) \mathrm{D}<25 \mathrm{nmol} / \mathrm{l}$ as the risk point for diabetic foot infection. Age, duration of diabetes and HbA1c were significantly higher in patients with diabetic foot infection than in patients with diabetes, and were therefore adjusted to nullify their effect, if any, on vitamin D concentration. It is a preliminary study with a lacuna that the effect of vitamin D deficiency on immunological parameters was not studied directly, as the aim was to determine the prevalence of vitamin D deficiency in diabetic foot infection. The effect of vitamin $\mathrm{D}$ deficiency and replacement on various immunological parameters could be incorporated in the future plan of similar studies. The strength of our present study is that the cut-off value of $<25 \mathrm{nmol} / 1$ had a significant relationship with the poor host defence against bacterial infection in diabetic foot and that this also indicates a new cut-off of vitamin D deficiency for immune dysfunction.

In conclusion, the study supports the hypothesis that vitamin $\mathrm{D}$ deficiency is more prevalent and severe in diabetic foot infection. The level of vitamin D observed to influence Ca homeostasis is possibly lower for enhancing susceptibility to infection in patients with diabetes. This study opens up an issue of recognising vitamin D deficiency as a possible risk factor for diabetic foot infections and suggests the need for vitamin D supplementation in such patients to prevent or to adjuvant the antibiotic therapy for control of infection.

\section{Acknowledgements}

The present study was supported partially by the University Grants Commission (UGC), New Delhi, India in the form of Grant P-01/613. The authors are thankful to Dr Chinmay Bera, Junior Resident of the Endocrinology and Metabolism Department for his help in patient recruitment in the study. S. T. collected the sample and data, performed the experiments, analysed the data and wrote the manuscript. D. D. P. collected and analysed the data, and helped in manuscript preparation. B. G. and A. D. helped in manuscript preparation. S. C. helped in sample collection. R. K. R. performed the statistical analysis. S. K. G. provided the sample, and reviewed and edited the manuscript. S. K. S. speculated the research question, designed and conducted the study, and edited the manuscript. S. T. and D. D. P. acknowledge the UGC for providing them Junior and Senior Research Fellowships, respectively. B. G. is thankful to the UGC for the project fellowship. A. D. is thankful to the Indian Council for Medical Research (ICMR), New Delhi, India for offering a Junior Research Fellowship. Part of this study has been presented in the Diabetes India 2011 conference. The authors declare that there are no conflicts of interest.

\section{References}

1. Baeke F, Etten EV, Overberg L, et al. (2007) Vitamin $\mathrm{D}_{3}$ and immune system: maintaining the balance in health and disease. Nutr Res Rev 20, 106-118.

2. Cantorna MT, Zhu Y, Froicu M, et al. (2004) Vitamin D status, 1,25-dihyroxyvitamin D3, and the immune system. Am J Clin Nutr 80, 17S-20S.

3. Chiu KC, Chu A, Go VL, et al. (2004) Hypovitaminosis D is associated with insulin resistance and beta cell dysfunction. Am J Clin Nutr 79, 820-825.

4. Veldman CM, Cantorna MT \& DeLuca HF (2000) Expression of 1,25 dihydroxyvitamin D3 receptor in the immune system. Arch Biochem Biophys 374, 334-338.

5. Kawarau AE, Takeda NT, Nakagawa K, et al. (2006) Inhibitory effect of long term 1-alpha-hydroxyvitamin D3 administration on Helicobacter pylori infection. J Clin Biochem Nutr 38, 103-106.

6. James RS, Paolo DP, Ralph JC, et al. (2010) Serum 25-hydroxyvitamin D and the incidence of acute viral respiratory tract infections in healthy adults. PLoS One 5, e11088.

7. Lavin ME \& O'Neal LW (1988) The Diabetic Foot, pp. 203-205. St Louis: CW Mosby Co. 
8. Geerlings SE \& Hoepelman AIM (1999) Immune dysfunction in patients with diabetes mellitus (DM). FEMS Immunol Med Microbiol 26, 259-265.

9. Hayes CE, Nashold FE, Spach KM, et al. (2003) The immunological functions of the vitamin D endocrine system. Cell Mol Biol 49, 277-300.

10. Mattila C, Knekt P, Mannisto S, et al. (2007) Serum 25-hydroxyvitamin D concentration and subsequent risk of type 2 diabetes. Diabetes Care 30, 2569-2570.

11. Michael FH, Neil CB, Heike ABF, et al. (2011) Treatment, and prevention of vitamin D deficiency: an Endocrine Society clinical practice guideline. J Clin Endocrinol Metab 96, 1911-1930

12. Institute of Medicine (2011) Dietary Reference Intakes for Calcium and Vitamin D. Washington, DC: The National Academies Press.

13. Marhoffer W, Stein M, Maeser E, et al. (1992) Impairment of polymorphonuclear leukocyte function and metabolic control of diabetes. Diabetes Care 15, 256-260.

14. Oncul O, Yildiz S, Gurer US, et al. (2007) Effect of the function of polymorphonuclear leukocytes and interleukin-1 beta on wound healing in patients with diabetic foot infections. J Infect 54, 250-256.
15. Doxey DL, Nares S, Park B, et al. (1998) Diabetes-induced impairment of macrophage cytokine release: role of serum lipids. Life Sci 63, 1127-1136.

16. Van EE, Decallonne B, Bouillon R, et al. (2004) NOD bone marrow-derived dendritic cells are modulated by analogs of 1,25-dihydroxyvitamin D(3). I Steroid Biochem Mol Biol 89-90, 457-459.

17. Helming L, Bose J \& Ehrchen J (2005) 1 1 2,25 -Dihydroxyvitamin D3 is a potent suppressor of interferon $\gamma$-mediated macrophage activation. Blood 106, 4351-4358.

18. Van EE \& Mathieu C (2005) Immunoregulation by 1,25-dihydroxyvitamin D3: basic concepts. J Steroid Biochem Mol Biol 97, 93-101.

19. Liu PT, Stenger S \& Tang DH (2007) Cutting edge: vitamin Dmediated human antimicrobial activity against Mycobacterium tuberculosis is dependent on the induction of cathelicidin. J Immunol 179, 2060-2063.

20. Kayaniyil S, Vieth R, Retnakaran R, et al. (2010) Association of vitamin $D$ with insulin resistance and $\beta$ cell dysfunction in subjects at risk for type 2 diabetes. Diabetes Care 33, 1379-1381.

21. Pittas AG, Harris SS, Stark PC, et al. (2007) The effects of calcium and vitamin D supplementation on blood glucose and markers of inflammation in nondiabetic adults. Diabetes Care 30, 980-986. 